\title{
BMJ Open Determinants of completion of advance directives: a cross-sectional comparison of 649 outpatients from private practices versus 2158 outpatients from a university clinic
}

Jochen Pfirstinger, ${ }^{1,2}$ Bernhard Bleyer, ${ }^{3,4}$ Christian Blum, ${ }^{5}$ Michael Rechenmacher, ${ }^{2}$ Christoph H Wiese, ${ }^{6,7}$ Hans Gruber ${ }^{5,8}$

To cite: Pfirstinger J, Bleyer B, Blum C, et al. Determinants of completion of advance directives: a cross-sectional comparison of 649 outpatients from private practices versus 2158 outpatients from a university clinic. BMJ Open 2017;7:e015708. doi:10.1136/ bmjopen-2016-015708

- Prepublication history for this paper is available online. To view these files, please visit the journal online (http://dx.doi. org/10.1136/bmjopen-2016015708).

Received 23 May 2017

Revised 24 0ctober 2017

Accepted 8 November 2017

CrossMark

For numbered affiliations see end of article.

Correspondence to Dr Jochen Pfirstinger; pfirstinger.jochen@klinikumamberg.de

\section{ABSTRACT}

Objectives To compare outpatients from private practices and outpatients from a university clinic regarding the determinants of completion of advance directives (AD) in order to generalise results of studies from one setting to the other. Five determinants of completion of $A D$ were studied: familiarity with $A D$, source of information about $A D$, prior experiences with own life-threatening diseases or family members in need of care and motives in favour and against completion of $A D$.

Design Observational cross-sectional study.

Setting Private practices and a university clinic in Germany in 2012.

Participants 649 outpatients from private practices and 2158 outpatients from 10 departments of a university clinic.

Outcome measures Completion of $A D$, familiarity with $A D$, sources of information about $A D$ (consultation), prior experiences (with own life-threatening disease and family members in need of care), motives in favour of or against completion of $A D$, sociodemographic data.

Results Determinants of completion of $A D$ did not differ between outpatients from private practices versus university clinic outpatients. Prior experience with severe disease led to a significantly higher rate of completion of $A D(33 \% / 36 \%$ with vs $24 \% / 24 \%$ without prior experience). Participants with completion of $A D$ had more often received legal than medical consultation before completion, but participants without completion of $A D$ are rather aiming for medical consultation. The motives in favour of or against completion of $A D$ indicated inconsistent patterns.

Conclusions Determinants of completion of $A D$ are comparable in outpatients from private practices and outpatients from a university clinic. Generalisations from university clinic samples towards a broader context thus seem to be legitimate. Only one-third of patients with prior experience with own life-threatening diseases or family members in need of care had completed an $A D$ as expression of their autonomous volition. The participants' motives for or against completion of $A D$ indicate that $A D s$ are considered a kind of 'negative autonomy' as instruments to prevent particular forms of therapy. Interactive, repeated and situation-based AD
Strengths and limitations of this study

- Our study includes a very large number of completed questionnaires regarding determinants of completion of $A D$. Data on the response rate to the survey were not collected.

- The questionnaire had been developed from a previous study and had been refined in a preliminary interview study, but has not run through a structured validation process.

- The comparison between outpatients from private practices and university clinic outpatients indicates that generalisations from university clinic samples towards a broader context seem to be legitimate.

- However, our study was conducted in a mediumsized town with rural surroundings, so that our regional findings may be inapplicable in metropolitan areas with people from many different nationalities.

discussions might reach a higher percentage of patients and concurrently enable personal volitions and thereby strengthen individual 'positive autonomy'.

\section{INTRODUCTION}

Life-threatening diseases and end-of-life decisions are an existential challenge for the relationship between patients and physicians. The physicians consider the indication of a medical intervention taking into account the principles of beneficence, best interests and futility. The relationship between patients and doctors has changed over the last decades from a paternalistic role model, where always the doctor decides what is best for a patient, to a patient-centred model, where autonomous patients are being informed by their doctors and then reach their own decisions. However, in end-of-life situations clinical experience has shown that the majority of patients use their autonomy 
for the prevention of, for example, suffering or getting connected to machines representing a kind of 'negative autonomy'. The concept of patient autonomy and the necessity of an informed consent for all medical interventions have become the fundamental principles for every interaction between patients and medical professionals. In cases of impaired decision-making capacity, advance directives (ADs) can be used to express the patient's will. In Germany, ADs are regulated by the third act amending German guardianship legislation, effective from 1 September 2009. As in many other countries, ADs comprise the following legal instruments: living will and healthcare proxy. By completing a living will, a patient can record legally binding instructions for or against future medical interventions that would otherwise be medically indicated. Patient autonomy can also be exercised by assigning a healthcare proxy, who makes healthcare decisions on behalf of the patient, when he or she is incapable of making those decisions.

Despite the considerable role of patient autonomy in all medical and legal decisions, only a minority of patients complete an $\mathrm{AD}$. A rate of $<40 \%$ is found in patients with cancer $^{1-3}$ and in the elderly population. ${ }^{4-7}$ An even lower rate is found in the general population. ${ }^{8-12}$ Educational interventions to promote $\mathrm{AD}$ slightly increase the completion rate, which still remains below $50 \% .^{13-15}$

A prior investigation of our group published in 2014 revealed that in almost 400 patients with cancer a substantial percentage of patients who had not yet completed an $\mathrm{AD}$ were willing to receive $\mathrm{AD}$ consultations 'now' or 'in a few weeks', but longitudinal analyses showed that in fact none of these patients made an appointment. The same percentage of patients with cancer postponed $\mathrm{AD}$ consultations, because an $\mathrm{AD}$ 'is not relevant' now or they 'do not want to get involved in this issue'. Only a small proportion completely rejected the offer of $\mathrm{AD}$ consultations. ${ }^{16}$ In summary, only a minority of all patients who visit a private practice or university outpatient clinic had in advance completed an AD. The majority either postpone completion of $\mathrm{AD}$ or even refuse to engage in discussion of $\mathrm{AD}$ issues. Two main determinants that impact completion of $\mathrm{AD}$ are age (older people are more likely to have completed an $\mathrm{AD}$ ) and duration of a cancer diagnosis (longer duration is positively associated with completion of an $\mathrm{AD}) .^{16-18}$

It is plausible that several other determinants play a role in patient decisions regarding the completion of ADs, including the source of information and prior experience with own life-threatening diseases or with family members in need of care. However, little is known from clinical studies about these determinants. ${ }^{19-22}$ Whether patients have stable end-of-life preferences is still an open question. ${ }^{23}$

Healthcare research is usually performed either in centres such as university hospitals or in a very decentralised setting. Whether samples from university clinics legitimately can be compared with samples from private practices providing general primary care is an open question. Duration of diagnoses, severity of illnesses and the professional training of medical staff might contribute to differences of patient selection and thus also of completion of $\mathrm{AD}$. However, a long-term trusting relationship to a family doctor may be a good basis for burdensome AD discussions leading to a higher completion rate. Therefore, studies using samples from university clinics are at risk of producing results that are not widely applicable in other settings. To our knowledge, determinants of completion of $\mathrm{AD}$ have not yet been investigated in a study that compares outpatients from a university clinic with outpatients from private practices.

We, therefore, conducted a study in a university clinic and in private practices in the same city. The objectives were to compare outpatients from private practices and outpatients from a university clinic regarding their familiarity with $\mathrm{AD}$, their source of information about $\mathrm{AD}$, their prior experience with own life-threatening disease or family members in need of care and their motives in favour and against completion of $\mathrm{AD}$.

\section{PATIENTS AND METHODS \\ Design}

The study was conducted as an observational crosssectional study. Two groups of participants were compared: outpatients from private practices and outpatients from a university clinic.

\section{Participants}

Eligibility criteria for participation in the study included a minimum age of 18 years, the ability to provide informed consent and being an outpatient. Participants were either outpatients from a university clinic or outpatients from private practices. The university clinic group was a convenience sample of 2158 outpatients cared for at 10 outpatient departments located at a German university clinic. These included clinics for radiotherapy, haematology and oncology, gastroenterology, endocrinology, rheumatology, infectious diseases, surgery, trauma surgery, craniofacial surgery and maxillofacial surgery, neurosurgery, otorhinolaryngology, dermatology, ophthalmology, cardiology, nephrology and pulmonology. The private practices group was a convenience sample of 649 outpatients from 18 private practices in the same city as the university clinic. The overall sample size was 2807. Data on the response rate to the survey were not collected.

\section{Procedure and instruments}

Based on items from a literature search and from a previous investigation about ADs in patients with cancer, ${ }^{16}$ we developed a preliminary questionnaire, which was applied in an interview study with 70 patients. After deletion of redundant or inappropriate items, we established a final questionnaire, which in six sections comprised dichotomous questions and multiple response questions: (1) information about the purpose of the study and request for informed consent, (2) sociodemographic 
Table 1 Characteristics of participants enrolled in the study, separately for outpatients of a university clinic and outpatients from private practices

\begin{tabular}{|c|c|c|}
\hline Characteristics & $\begin{array}{l}\text { Outpatients from a university clinic } \\
\left(N_{1}=2158\right)\end{array}$ & $\begin{array}{l}\text { Outpatients from private practices } \\
\left(\mathrm{N}_{2}=649\right)\end{array}$ \\
\hline Age $\left(n_{1}=2122 ; n_{2}=622\right)$ & $52(15)$ & $52(17)$ \\
\hline Women $\left(n_{1}=2151 ; n_{2}=648\right)$ & $1027(48)$ & $423(65)$ \\
\hline \multicolumn{3}{|l|}{ Type of disease $\left(n_{1}=1746 ; n_{2}=444\right)$} \\
\hline Tumour disease & $426(24)$ & $30(7)$ \\
\hline Donor organ & $165(10)$ & $5(1)$ \\
\hline Never been seriously ill & $438(25)$ & $280(63)$ \\
\hline Other chronic illness & $580(33)$ & $118(27)$ \\
\hline Proxy & $137(8)$ & $11(2)$ \\
\hline \multicolumn{3}{|l|}{ Marital status $\left(n_{1}=2153 ; n_{2}=643\right)$} \\
\hline Never married & 377 (18) & $119(19)$ \\
\hline Married/cohabitation & $1508(70)$ & $431(67)$ \\
\hline Divorced & $153(7)$ & $45(7)$ \\
\hline Widowed & $115(5)$ & $48(7)$ \\
\hline \multicolumn{3}{|l|}{ Education $\left(n_{1}=2119 ; n_{2}=630\right)$} \\
\hline Secondary education (nine grades) & $982(46)$ & $266(42)$ \\
\hline Secondary education (10 grades) & $645(31)$ & $226(36)$ \\
\hline A level (13 grades) & $423(20)$ & $118(19)$ \\
\hline Elementary (grades 1-4) & $69(3)$ & $20(3)$ \\
\hline \multicolumn{3}{|l|}{ Qualification $\left(n_{1}=2081 ; n_{2}=619\right)$} \\
\hline Non-academic professional & $1598(77)$ & $482(78)$ \\
\hline Academic professional & $318(15)$ & $92(15)$ \\
\hline No professional qualification & $165(8)$ & $45(7)$ \\
\hline \multicolumn{3}{|l|}{ Location $\left(n_{1}=2127 ; n_{2}=643\right)$} \\
\hline Urban area & $588(28)$ & $213(33)$ \\
\hline Rural area & 1539 (72) & $430(67)$ \\
\hline
\end{tabular}

Sample sizes $\left(n_{1}, n_{2}\right)$ for particular variables differ from the total sample sizes $\left(N_{1}, N_{2}\right)$ due to missing values. For age, the means (SD in brackets) in years are given. For all other variables, the numbers of participants (percentages in brackets) are given

questions (see table 1), (3) familiarity with and existence of $\mathrm{AD},(4)$ questions about preferences regarding sources of information (eg, whom the patient would like to consult about completion of an $\mathrm{AD}),(5)$ questions about prior experiences with own life-threatening diseases or family members in need of care, and (6) questions about motives in favour of or against the completion of $\mathrm{AD}$. The final version of the questionnaire listed 10 different motives in favour and 13 motives against the completion of $\mathrm{AD}$ with multiple answers allowed. The study was approved by the institutional ethics committee at the Regensburg University Hospital.

During March to June 2012, patients of the above-mentioned university clinics and private practices received the questionnaire from the clinic staff or the doctor's assistant as they signed up for their medical examination. The participants were requested to read the introduction and to complete the questionnaire while waiting for their appointment. At the end of their visits, they returned the filled questionnaires to the registration.

\section{Statistical analysis}

The analyses aimed at comparing the university clinic group and the private practice group regarding the determinants of completion of $\mathrm{AD}$ (familiarity with $\mathrm{AD}$, source of information about $\mathrm{AD}$, prior experience with own lifethreatening disease or family members in need of care and motives in favour of and against completion of $\mathrm{AD}$ ). Data are presented in the form of proportions for categorical variables and means (and SD) for continuous variables. $\chi^{2}$ tests, the $\Phi$ coefficient, Cramer's $V$ and the OR were used to detect statistically significant and clinically relevant group differences. All reported $\mathrm{P}$ values are two-sided, with $\mathrm{P}<0.05$ considered as significant. Data were analysed with SPSS software, V.21.

\section{RESULTS}

The results are presented in the following order. After providing descriptive information on the two groups, outpatients from a university clinic and outpatients from 
private practices, the results concerning the comparison of the two groups regarding determinants of completion of $\mathrm{AD}$ are displayed (familiarity with $\mathrm{AD}$, source of information about $\mathrm{AD}$, prior experience with own life-threatening diseases or family members in need of care, motives in favour of and against completion of $\mathrm{AD}$ ).

\section{Descriptives}

Table 1 shows the absolute and relative frequencies of age, gender, type of disease and sociodemographic characteristics (marital status, education, qualification, location) of the participants in each group.

Except for gender and type of disease, the groups did not significantly differ. In the private practice group, there was a higher proportion of female participants than in the university clinic group $\left(\chi^{2}(1)=61.31 ; \mathrm{P}=0.001 ; \Phi=0.148\right)$. The university clinic group included more participants with a malignancy and more participants after organ transplantation. Most participants in the private practice group had never been seriously ill $\left(\chi^{2}(4)=260.23\right.$; $\mathrm{P}=0.001 ; V=0.345)$. These two variables did not confound any of the following results.

\section{Familiarity with AD, completion of AD}

Among the sample, 2594 (92\%) participants were familiar with living wills, and $1826(65 \%)$ participants were familiar with healthcare proxies, the two forms of AD. Of those who were familiar with the instruments of ADs, 781 $(30 \%)$ participants had completed a living will, and 617 (34\%) participants had completed a healthcare proxy. A total of 1783 (64\%) participants (university clinic: 1340; private practices: 443) were familiar with both instruments, of which 559 (20\%) persons (university clinic: 418; private practices: 141 ) had completed both a living will and a healthcare proxy. Thus, only about one-third of the participants had previously completed a living will and/ or a healthcare proxy. The data show that the sampled outpatients were more familiar with living wills than with healthcare proxies.

Table 2 shows the familiarity with $\mathrm{AD}$ and the presence of $\mathrm{AD}$ for both groups.

There was no substantial difference between the groups in completion of $\mathrm{AD}$ (living will: $\chi^{2}(1)=0.006 ; \mathrm{P}=0.938$; healthcare proxy: $\left.\chi^{2}(1)=0.02 ; \mathrm{P}=0.899\right)$, and in familiarity with living wills $\left(\chi^{2}(1)=1.36 ; \mathrm{P}=0.242\right)$. However, the groups significantly differed with regard to familiarity with healthcare proxies $\left(\chi^{2}(1)=10.21 ; \mathrm{P}=0.001 ; \Phi=0.061\right.$, $\mathrm{OR}=1.37)$.

\section{Source of information for completion of AD}

Before the completion of $\mathrm{AD}, 715$ (92\%) participants informed themselves. A total of $509(65 \%)$ participants stated that they had discussed their decision to complete an AD with a confidant several times. Another 204 (26\%) participants discussed their decision only once, and 38 (5\%) participants had no conversation at all with a confidant about their AD. In both samples, the correlation proved significant between having an $\mathrm{AD}$ and having had multiple discussions with a confidant (university clinic: $\chi^{2}(2)=395.04 ; \mathrm{P}<0.001 ; V=0.433$; private practices: $\left.\chi^{2}(2)=115.64 ; \mathrm{P}<0.001 ; V=0.434\right)$. Whereas most participants talked at least once to a confidant about completion of $\mathrm{AD}$, only a minority asked for professional advice: 173 (22\%) participants consulted a physician and 280 $(36 \%)$ participants consulted a lawyer.

Participants who had not yet completed an AD (1998) reported different preferred sources of information. When asked by whom they want to be counselled, 1519 $(76 \%)$ participants wished to be informed by a physician, whereas only $115(6 \%)$ participants wished to be informed by a lawyer (see table 3 ).

The comparison of the samples of outpatients from a university clinic and outpatients from private practices revealed no significant differences regarding sources of information before completion of $\mathrm{AD}$ (all $\mathrm{P}$ values $>0.05$ ). When only participants without completion of $\mathrm{AD}$ were analysed, statistically significant differences between the two groups were noted. A larger percentage of participants in the private practice group, compared with the university clinic group, wanted to be informed about $\mathrm{AD}$ by their family physician $\left(\chi^{2}(1)=15.49 ; \mathrm{P}=0.001 ; \Phi=0.09\right.$, $\mathrm{OR}=1.55$ ). In contrast, participants from the university clinic group more often wanted to be informed about $\mathrm{AD}$ by a clinician $\left(\chi^{2}(1)=19.19 ; \mathrm{P}=0.001 ; \Phi=0.10, \mathrm{OR}=2.43\right)$. However, the effect sizes were only small. No difference between the two groups could be found as to their preference to be counselled by a lawyer.

Table 2 Familiarity with and presence of advance directives (separate for living wills and for healthcare proxies), separately for outpatients from a university clinic and for outpatients from private practices

\begin{tabular}{lll}
\hline & $\begin{array}{l}\text { Outpatients from a university } \\
\text { clinic } \\
\left(\boldsymbol{N}_{\mathbf{1}}=\mathbf{2 1 5 8 )}\right.\end{array}$ & $\begin{array}{l}\text { Outpatients from private } \\
\text { practices } \\
\left(\boldsymbol{N}_{\mathbf{2}}=649\right)\end{array}$ \\
\hline Familiarity with living will $\left(n_{1}=2146 ; n_{2}=638\right)$ & $1993(93)$ & $601(94)$ \\
\hline Familiarity with healthcare proxy $\left(n_{1}=2132 ; n_{2}=634\right)$ & $1374(64)$ & $452(71)$ \\
Presence of a living will $\left(n_{1}=1990 ; n_{2}=597\right)$ & $600(30)$ & $181(30)$ \\
\hline Presence of a healthcare proxy $\left(n_{1}=1366 ; n_{2}=443\right)$ & $467(34)$ & $150(34)$
\end{tabular}

Sample sizes $\left(n_{1}, n_{2}\right)$ for particular variables differ from the total sample sizes $\left(N_{1}, N_{2}\right)$ due to missing values. For all variables, the numbers of participants (percentages in brackets) are given 
Table 3 Sources of information about AD, separately for outpatients of a university clinic and outpatients from private practices

\begin{tabular}{ll}
$\begin{array}{l}\text { Outpatients of a university } \\
\text { clinic with completion of AD } \\
\left(N_{1}=600\right)\end{array}$ & $\begin{array}{l}\text { practices with completion of } \\
\left(N_{2}=181\right)\end{array}$ \\
\hline &
\end{tabular}

Participant self-informed before completion of $\mathrm{AD}\left(n_{1}=567 ; 548(97) \quad 167\right.$ (96)
$\left.n_{2}=174\right)$

Participant discussed her/his decision with a confidant

$\left(n_{1}=581 ; n_{2}=170\right)$

\begin{tabular}{|c|c|c|}
\hline Once & $154(27)$ & $50(29)$ \\
\hline Several times & $398(68)$ & $111(65)$ \\
\hline \multicolumn{3}{|c|}{ Participant was counselled $\left(n_{1}=593 ; n_{2}=174\right)$} \\
\hline By a physician & $143(24)$ & $30(17)$ \\
\hline \multirow[t]{2}{*}{ By a lawyer } & $215(36)$ & $65(37)$ \\
\hline & $\begin{array}{l}\text { University clinic outpatients } \\
\left(N_{1}=2158\right)\end{array}$ & $\begin{array}{l}\text { Private practice outpatients } \\
\left(\mathrm{N}_{2}=649\right)\end{array}$ \\
\hline \multicolumn{3}{|c|}{$\begin{array}{l}\text { Participant wants to be counselled }\left(n_{1}=1483 ; n_{2}=428\right) \\
\text { (multiple answers possible) }\end{array}$} \\
\hline By her/his family physician & $762(51)$ & $266(62)$ \\
\hline By a medical specialist & $213(14)$ & $35(8)$ \\
\hline By a clinician & $215(15)$ & $28(6)$ \\
\hline By a lawyer & $87(6)$ & $28(6)$ \\
\hline
\end{tabular}

Sample sizes $\left(n_{1}, n_{2}\right)$ for particular variables differ from the total sample sizes $\left(N_{1}, N_{2}\right)$ due to missing values. For all variables, the numbers of participants (percentages in brackets) are given

$A D$, advance directive.

Prior experiences with own life-threatening disease or family members in need of care

Prior familiarity with the instruments of advance care planning was associated with a higher rate of completion of $\mathrm{AD}$ (see table 2). Also, having either suffered from a life-threatening disease or cared for a dying family member was positively associated with completion of AD (see table 4). More participants who had cared for a relative until her/his death had completed an $\mathrm{AD}$

Table 4 Prior experience with own life-threatening diseases or family members in need of care and presence of $A D$

\begin{tabular}{lrl}
\hline & No AD & \multicolumn{1}{c}{$\begin{array}{l}\text { Completion } \\
\text { of AD }\end{array}$} \\
\hline $\begin{array}{l}\text { Cared for a family member until } \\
\text { her/his death }(\mathrm{N}=2672)^{*}\end{array}$ & \\
$\quad$ No & $1097(76)$ & $341(24)$ \\
$\quad$ Yes & $822(67)$ & $412(33)$ \\
$\begin{array}{l}\text { Suffered from a life-threatening } \\
\text { disease once before }(\mathrm{N}=2636)^{*}\end{array}$ & & \\
$\quad$ No & $1333(76)$ & $419(24)$ \\
$\quad$ Yes & $568(64)$ & $316(36)$ \\
\hline
\end{tabular}

${ }^{*} \mathrm{~N}$ on this variable differs from the total $\mathrm{N}$ due to missing values. For all variables, the numbers of participants (percentages in brackets) are given

$A D$, advance directive. compared with participants lacking such an experience $\left(\chi^{2}(1)=30.70 ; \mathrm{P}=0.001 ; \Phi=0.10, \quad \mathrm{OR}=1.61\right)$. Similarly, participants who had suffered from an own life-threatening disease had a higher rate of completion of $\mathrm{AD}$ than participants without this experience $\left(\chi^{2}(1)=40.89\right.$; $\mathrm{P}=0.001 ; \Phi=0.13, \mathrm{OR}=1.77$ ).

Although there was no significant difference between the two sample groups in the presence of an $\mathrm{AD}$, differences were found regarding prior experience with own life-threatening diseases. More participants in the private practice group had cared for a family member until her/ his death than participants in the university clinic group. However, the effect size was small $\left(\chi^{2}(1)=8.62 ; \mathrm{P}=0.003\right.$; $\Phi=0.06, \mathrm{OR}=1.31$ ). As expected, more participants from the university clinic group earlier had suffered from a life-threatening disease than participants from the private practice group $\left(\chi^{2}(1)=128.56 ; \mathrm{P}=0.001 ; \Phi=0.22\right.$, $\mathrm{OR}=3.75)$.

\section{Motives in favour of completion of AD}

The most frequent motives in favour of completion of $\mathrm{AD}$ were to prevent unnecessary suffering $(68 \%)$, followed by the avoidance of being a burden for others (55\%). For additional but less frequently reported motives see table 5 (multiple answers were possible).

No significant differences were found between the university clinic group and the private practice group except for the avoidance of being a burden, which was 
Table 5 Motives in favour of completion of AD (multiple answers possible)

\begin{tabular}{llll}
\hline Participant completed an AD because... & $\begin{array}{l}\text { Total } \\
(\mathbf{N}=\mathbf{7 3 6})^{*}\end{array}$ & $\begin{array}{l}\text { Outpatients of a } \\
\text { university clinic } \\
\left(\boldsymbol{n}_{\mathbf{1}}=\mathbf{5 6 7}\right)\end{array}$ & $\begin{array}{l}\text { Outpatients of } \\
\text { private practices } \\
\left(\boldsymbol{n}_{\mathbf{2}}=\mathbf{1 6 9}\right)\end{array}$ \\
\hline She/he does not want to suffer unnecessarily & $504(68)$ & $385(68)$ & $119(70)$ \\
She/he does not want to be a burden to anyone & $402(55)$ & $297(52)$ & $105(62)$ \\
Physicians are instructed to do everything possible to preserve one's life & $250(34)$ & $186(33)$ & $64(38)$ \\
She/he wants to make her/his own decisions & $231(31)$ & $183(32)$ & $48(28)$ \\
She/he distrusts physicians to decide in her/his best interest & $178(24)$ & $131(23)$ & $47(28)$ \\
She/he has had experiences with intense care for relatives & $164(22)$ & $127(22)$ & $37(22)$ \\
She/he completed it in the course of receiving legal advice & $130(18)$ & $95(17)$ & $35(21)$ \\
She/he distrusts her/his relatives to decide in her/his best interest & $88(12)$ & $68(12)$ & $20(11)$ \\
\hline
\end{tabular}

${ }^{*} \mathrm{~N}$ on this variable differs from the total $N$ due to missing values.

For all variables, the numbers of participants (percentages in brackets) are given.

$A D$, advance directive.

reported as a motive more often by participants of the private practice group $\left(\chi^{2}(1)=5.01 ; \mathrm{P}=0.025 ; \Phi=0.08\right.$, $\mathrm{OR}=1.49)$. Due to the small effect size, there is only limited practical significance. Among those 130 participants who completed an $\mathrm{AD}$ in the course of receiving legal advice, only 16 had consulted a physician in addition. Furthermore, among those who already had completed an $\mathrm{AD}$, only $231(31 \%)$ indicated that they 'wanted to make his/ her own decisions'.

\section{Motives against completion of $A D$}

"I currently do not want to deal with the issue" was the most frequently reported motive $(588 ; 35 \%)$ against completion of AD, followed by "I am too young" (321; $19 \%$ ). For additional but less frequently reported motives see table 6 (multiple answers were possible).

The comparison of the patients from the university clinic group and the patients from the private practice group revealed no relevant differences.

Inconsistent response patterns were revealed by cross tabulating the motives against completion of $\mathrm{AD}$ with the question of when it is appropriate to complete one. Among those participants who stated that they were currently not willing to address this issue $(\mathrm{n}=555)$, $318(57 \%)$ participants stated that the completion of AD should be considered early, and 145 (26\%) participants agreed with the statement that an $\mathrm{AD}$ should be completed no matter whether one is suffering from a disease or not. A similar pattern was found among those who argued that they were too young to complete an $\mathrm{AD}(\mathrm{n}=314) ; 177(56 \%)$ of them agreed that completion of $\mathrm{AD}$ should be done early, and 78 (25\%) indicated that one should complete an $\mathrm{AD}$ independently of the presence of a disease.

Some of the participants voluntarily provided comments in addition to the questionnaire answers. Among the 325 participants providing such comments, $172(53 \%)$ stated that they just postponed completion of AD or were simply too idle. However among the 1998 participants without completion of $\mathrm{AD}, 1643$ (82\%) were willing to discuss this issue.

Table 6 Motives against completion of AD (multiple answers possible)

\begin{tabular}{llll}
\hline Participant did not yet complete an AD because... & $\begin{array}{l}\text { Total } \\
\mathbf{( N = 1 6 6 5 )}\end{array}$ & $\begin{array}{l}\text { Outpatients of a } \\
\text { university clinic } \\
\left(\boldsymbol{n}_{\mathbf{1}}=\mathbf{1 2 8 5}\right)\end{array}$ & $\begin{array}{l}\text { Outpatients of } \\
\text { private practices } \\
\left(\boldsymbol{n}_{\mathbf{2}}=\mathbf{3 8 0}\right)\end{array}$ \\
\hline $\begin{array}{l}\text { She/he currently does not want to deal with this issue } \\
\text { She/he is too young }\end{array}$ & $588(35)$ & $468(36)$ & $120(32)$ \\
Her/his attitude could change during the progression of a disease & $2721(19)$ & $246(19)$ & $75(19)$ \\
Medical treatment options could improve & $226(14)$ & $222(17)$ & $57(17)$ \\
She/he delegates the decision to a specialist in case of emergency & $215(13)$ & $186(15)$ & $40(11)$ \\
She/he feels insecure with legal regulations & $202(12)$ & $160(12)$ & $43(11)$ \\
She/he fears giving the wrong instructions & $176(11)$ & $144(11)$ & $42(11)$ \\
She/he cannot appraise the listed medical treatments & $136(8)$ & $113(9)$ & $23(6)$ \\
\hline
\end{tabular}

${ }^{*} \mathrm{~N}$ on this variable differs from the total due to missing values.

For all variables, the numbers of participants (percentages in brackets) are given.

$A D$, advance directive. 


\section{Limitations}

Some limitations to the present research also warrant attention. First, the psychometrics of the used questionnaire are unknown. The questionnaire had been employed in previous research and had been revised in a preliminary interview study; nevertheless, a structured validation process is still lacking. Second, no information on the response rate to the survey was gathered. Thus, the representativeness of the study's sample is uncertain. In light of these caveats and despite the large sample size, the study results have to be interpreted cautiously.

\section{DISCUSSION}

The issue of patient autonomy, despite its undisputable relevance, still poses many open questions. Many actors in Germany-both from policy and from medicine-are disappointed by the low percentage of people who have already completed an $\mathrm{AD}$. It is not trivial to investigate the reasons preventing people from completion of $\mathrm{AD}$. In this study, a number of attempts were undertaken in order to better understand the issue. First, a large sample size was used in order to increase the reliability and trustworthiness of the answers provided by the participants: more than 2800 participants were studied. Second, the major research question was to investigate whether the motives in favour of or against completion of $\mathrm{AD}$ resembled each other in two different groups of patients: outpatients from a university clinic (many of whom suffer from life-threatening diseases) and outpatients from private practices. Determinants of completion of AD previously mainly have been studied within university clinic patients. Whether the results can legitimately be generalised towards a broader population is still an open question, thus addressing the societal need to broadly discuss the issue of $\mathrm{AD}$. A number of reasons were mentioned in prior research indicating that the experience of suffering from a life-threatening disease might influence the importance of making decisions related to patient autonomy. ${ }^{22}$ The results show, however, that outpatients from a university clinic do not significantly differ from outpatients from private practices regarding most determinants of completion of $\mathrm{AD}$. A broad number of such determinants were investigated, among them the sources of information about $\mathrm{AD}$, that is, to what degree professional consultation had been requested before completion of $\mathrm{AD}$, and from which professional groups such advice had been requested. In addition, it was investigated whether those without completion of $\mathrm{AD}$ would like to receive professional advice-and, again, by whom-before making a decision in favour of completion of AD. Motives both in favour of and against completion of $\mathrm{AD}$ were investigated.

Concerning the comparability of samples from a university clinic and from private practices, and thus of the generalisability of results, few differences were found between the two groups indicating that the results legitimately may be generalised. The group of outpatients from private practices was slightly more familiar with healthcare proxies, but the effect size was very small. In general, however, the groups did not differ significantly. These results, based on a large sample size, are a strong indicator that future studies might rely on results from either of those two samples. The percentage of those who had completed an AD was of the same size (about 30\%) as in the general population. In both groups, the percentage was a bit higher (33\% and 36\%, respectively) among participants with prior experience of own life-threatening diseases. This matches findings from other studies, ${ }^{22}$ but still leaves the question open why even those participants do not make much more use of the instruments of patient autonomy. Prior experience (either individual or related to one's family) with life-threatening diseases, intensive care treatment, nursing cases and so on only slightly increased the rate of completion of $\mathrm{ADs}$, and only to a level still clearly below $50 \%$.

Concerning the question of seeking professional consultation, both before completion of $\mathrm{AD}$ and the intention of completion in the future, our study was consistent with prior findings that more than one-third of the patients with completion of $\mathrm{AD}$ had received legal advice. ${ }^{1624}{ }^{25}$ In some patients, legal consultation about $\mathrm{AD}$ may be related to receiving legal testament advice, as it has been shown that patients were much more likely to complete an $\mathrm{AD}$ when asked by legal staff compared with medical staff. ${ }^{26}$ Among those who have not yet completed an $\mathrm{AD}$, many stated their desire for professional advice, with a large majority preferring medical consultation to legal advice. The results match prior studies' finding that almost every patient considers ADs as something very important which should be completed early. ${ }^{1}$ It should be noted that acceptance rates for completion of $\mathrm{AD}$ close to $100 \%$ can be found in interview data, which may reflect what is socially desirable. In contrast, none of the multiple interventions to promote completion of $\mathrm{AD}$ increased the rate above $50 \%$, which may reflect that patient autonomy rests on a voluntary basis. ${ }^{13}$ The deviation of the patients' intention to their acting can be explained as an example of the mind-behaviour-gap theory. ${ }^{27}$

In the group of outpatients from private practices, the family doctor frequently was named as the preferred person of trust for $\mathrm{AD}$ consultations. However, in the university clinic setting, the result was in favour of hospital physicians. Therefore, it can be concluded that patients are open to receive $\mathrm{AD}$ consultations, wherever they are treated.

A first step to initiate discussions about ADs often is made as a by-product of other issues, for example, the case in a legal advice setting, when a testament consultation is followed by a consultation about an AD. An important second step would be the trustful interaction with the family doctor. The results show that many participants felt confused by the legal regulation. In contrast to lawyers, however, family physicians do not receive a financial incentive when they involve themselves in consultations about ADs. It is reported that such consultation often takes a considerable amount of time, as it may easily exceed $30 \mathrm{~min}$. Providing an adequate financial compensation to 
family physicians for consultation around ADs could be a promising approach to promote completion of ADs.

Concerning the motives in favour of or against completion of $\mathrm{AD}$, the study revealed some inconsistent response patterns that need further analysis or even a fresh theoretical perspective on the issue. Inconsistencies were revealed when cross tabulating the motives against completion of $\mathrm{AD}$ with the question of when it is appropriate to complete an $\mathrm{AD}$. Possible explanations of these inconsistencies-although not deliberately investigated in this study-could be identified in comments, which 325 of the participants provided voluntarily in addition to the questionnaire answers. More than half of them stated that they just postponed completion of AD or were simply too idle. For example, one participant quoted: "Because I procrastinated completing a living will up to now." This finding was in line with the fact that more than $80 \%$ of the participants without completion of $\mathrm{AD}$ were willing to discuss this issue. Although most participants indicated being willing in principle to complete an $\mathrm{AD}$, many did not initiate the completion on their own. The majority of patients who had completed an $\mathrm{AD}$ had done so in reaction to distrust and fear of future treatments. ${ }^{28}$ Less than one-third of the participants who had completed an AD stated that they 'wanted to make his/her own decisions'.

These findings might pose new questions concerning the motives for completion of $\mathrm{AD}$. It might be that the findings indicate a kind of 'negative autonomy': living wills and healthcare proxies might be seen mainly as instruments to prevent particular forms of therapy, but not as instruments to design one's own 'positive autonomy'. Our preceding interview study (not published) revealed that the majority of patients consider living wills and healthcare proxies as something unpleasant, which must be done-sometime in the future-but not as a chance to actively take control of their lives. The questionnaire items were developed as a result of the interviews and were formulated to elicit positive and negative motives concerning completion of $\mathrm{AD}$. Our underlying intention was to find out whether patients' attitudes towards completion of $\mathrm{AD}$ could be influenced positively to achieve a higher completion rate. Future studies could investigate under which conditions patients are most motivated to think proactively about future medical decisions. This, however, would require a paradigm shift both in underlying research and in the practices how medical and legal professionals approach the issue of completion of $\mathrm{AD}$. In theory, ADs provide an opportunity for patients to exercise their autonomy and to actively engage in decisions about their future healthcare. In practice, however, ADs are primarily used as a means to prevent certain unwanted treatments or in negative reaction to prior personal experiences. The use of ADs has been largely reactive instead of proactive. To increase the uptake of ADs among patients, it may be necessary to reframe ADs as a means of engaging proactively in future healthcare decisions rather than as a reactive tool used to prevent future unwanted experiences.
Up to this point, most attempts to increase uptake of ADs among patients have focused on educating medical or legal professionals ${ }^{29} 30$ rather than focusing on methods to increase the patient's autonomy. The empirical evidence clearly demonstrates that most of these educational efforts have failed to successfully increase the usage of ADs by patients. Further studies are needed to investigate whether a different approach, with a focus on increasing patient autonomy and allowing patients to more proactively engage in decisions about their future healthcare, may be more successful in increasing the number of patients with a completion of AD. Further investigation is also warranted into whether patients might be more willing to engage in these decisions if the topic is presented by their trusted family physician as part of a discussion of future autonomy.

\section{Author affiliations}

${ }^{1}$ Department of Internal Medicine II, St. Marien Hospital Amberg, Amberg, Germany ${ }^{2}$ Department of Hematology, Regensburg University Hospital, Regensburg, Germany ${ }^{3}$ Institute of Sustainability, Ostbayerische Technische Hochschule Amberg-Weiden, Amberg, Germany

${ }^{4}$ Faculty of Catholic Theology, University of Regensburg, Regensburg, Germany ${ }^{5}$ Department of Educational Science, University of Regensburg, Regensburg,

Germany

${ }^{6}$ Department of Anaesthesiology, Regensburg University Hospital, Regensburg, Germany

${ }^{7}$ Department of Anaesthesiology, Herzogin Elisabeth Hospital, Braunschweig, Germany

${ }^{8}$ Faculty of Education, University of Turku, Turku, Finland

Contributors JP initiated the study as a further development of a previous study, made major contributions to the questionnaire and to the data interpretation, contributed to the data analysis and wrote large parts of the manuscript. BB made major contributions to the questionnaire and to the data interpretation, in particular with respect to the theological and ethical aspects, and helped writing and correcting the manuscript. CB conducted a preliminary interview study (not published), the results of which have been integrated into the questionnaire. He performed large parts of the data acquisition and of the statistical data analysis, contributed to the data interpretation and helped writing and correcting the manuscript. MR and CHW made significant contributions to the questionnaire and to the data interpretation and helped correcting the manuscript. HG initiated and supervised the preliminary interview study (not published), the results of which have been integrated into the questionnaire. He supervised the statistical data analysis, made major contributions to the questionnaire and to the data interpretation, in particular, with respect to educational and learning aspects and helped writing and correcting the manuscript.

Competing interests None declared.

Patient consent Obtained.

Ethics approval Ethics Committee of University Hospital Regensburg, Germany. Provenance and peer review Not commissioned; externally peer reviewed.

Data sharing statement All authors agree to make the relevant anonymised patient level data available for all researchers on reasonable written request to the corresponding author.

Open Access This is an Open Access article distributed in accordance with the Creative Commons Attribution Non Commercial (CC BY-NC 4.0) license, which permits others to distribute, remix, adapt, build upon this work non-commercially, and license their derivative works on different terms, provided the original work is properly cited and the use is non-commercial. See: http://creativecommons.org/ licenses/by-nc/4.0/

(c) Article author(s) (or their employer(s) unless otherwise stated in the text of the article) 2017. All rights reserved. No commercial use is permitted unless otherwise expressly granted. 


\section{REFERENCES}

1. Dow LA, Matsuyama RK, Ramakrishnan V, et al. Paradoxes in advance care planning: the complex relationship of oncology patients, their physicians, and advance medical directives. J Clin Oncol 2010;28:299-304.

2. McKinley ED, Garrett JM, Evans AT, et al. Differences in end-of-life decision making among black and white ambulatory cancer patients. J Gen Intern Med 1996;11:651-6.

3. Sahm S, Will R, Hommel G. What are cancer patients' preferences about treatment at the end of life, and who should start talking about it? A comparison with healthy people and medical staff. Support Care Cancer 2005;13:206-14.

4. Eleazer GP, Hornung CA, Egbert CB, et al. The relationship between ethnicity and advance directives in a frail older population. $J \mathrm{Am}$ Geriatr Soc 1996;44:938-43.

5. Morrison RS, Meier DE. High rates of advance care planning in New York City's elderly population. Arch Intern Med 2004;164:2421-6.

6. Samsi K, Manthorpe J. 'I live for today': a qualitative study investigating older people's attitudes to advance planning. Health Soc Care Community 2011;19:52-9.

7. Seymour J. Technology and "natural death": a study of older people. Z Gerontol Geriatr 2003;36:339-46.

8. Curtis JR. Communicating with patients and their families about advance care planning and end-of-life care. Respir Care 2000;45:1385-94.

9. Hickey DP. The disutility of advance directives: we know the problems, but are there solutions? J Health Law 2003;36:455-73.

10. Phipps E, True G, Harris D, et al. Approaching the end of life: attitudes, preferences, and behaviors of African-American and white patients and their family caregivers. J Clin Oncol 2003;21:549-54.

11. Rurup ML, Onwuteaka-Philipsen BD, van der Heide A, et al. Frequency and determinants of advance directives concerning endof-life care in The Netherlands. Soc Sci Med 2006;62:1552-63.

12. Teno JM. Advance directives: time to move on. Ann Intern Med 2004;141:159-60.

13. Bravo G, Dubois MF, Wagneur B. Assessing the effectiveness of interventions to promote advance directives among older adults: a systematic review and multi-level analysis. Soc Sci Med 2008;67:1122-32.

14. Furman CD, Head B, Lazor B, et al. Evaluation of an educational intervention to encourage advance directive discussions between medicine residents and patients. J Palliat Med 2006;9:964-7.

15. Meier DE, Fuss BR, O'Rourke D, et al. Marked improvement in recognition and completion of health care proxies. A randomized controlled trial of counseling by hospital patient representatives. Arch Intern Med 1996;156:1227-32.
16. Pfirstinger J, Kattner D, Edinger M, et al. The impact of a tumor diagnosis on patients' attitudes toward advance directives. Oncology 2014;87:246-56.

17. Blackhall LJ, Frank G, Murphy ST, et al. Ethnicity and attitudes towards life sustaining technology. Soc Sci Med 1999;48:1779-89.

18. Kierner KA, Hladschik-Kermer B, Gartner V, et al. Attitudes of patients with malignancies towards completion of advance directives. Support Care Cancer 2010;18:367-72.

19. Lang FR, Wagner GG. [Patient living wills in Germany: conditions for their increase and reasons for refusal]. Dtsch Med Wochenschr 2007;132:2558-62.

20. Morrison RS, Zayas LH, Mulvihill M, et al. Barriers to completion of health care proxies: an examination of ethnic differences. Arch Intern Med 1998;158:2493-7.

21. Morrison RS, Zayas LH, Mulvihill M, et al. Barriers to completion of healthcare proxy forms: a qualitative analysis of ethnic differences. $J$ Clin Ethics 1998;9:118-26.

22. Sahm S, Will R, Hommel G. Attitudes towards and barriers to writing advance directives amongst cancer patients, healthy controls, and medical staff. J Med Ethics 2005;31:437-40.

23. Auriemma CL, Nguyen CA, Bronheim R, et al. Stability of end-of-life preferences: a systematic review of the evidence. JAMA Intern Med 2014;174:1085-92.

24. Becker M, Jaspers B, King C, et al. Did you seek assistance for writing your advance directive? A qualitative study. Wien Klin Wochenschr 2010;122:620-5.

25. Bleyer B, Dörfler T, Gruber H, et al. Wer über mich verfügt, entscheide ich - und ein anderer. die patientenverfügung und das kommunizierte moralische urteil. ZME 2013;59:297-310.

26. Van Scoy LJ, Howrylak J, Nguyen A, et al. Family structure, experiences with end-of-life decision making, and who asked about advance directives impacts advance directive completion rates. J Palliat Med 2014;17:1099-106.

27. Schwarzer R. Modeling health behavior change: how to predict and modify the adoption and maintenance of health behaviors. Appl Psychol 2008;57:1-29.

28. Sahm S, Will R, Hommel G. Would they follow what has been laid down? Cancer patients' and healthy controls' views on adherence to advance directives compared to medical staff. Med Health Care Philos 2005;8:297-305.

29. Green MJ, Levi BH. Teaching advance care planning to medical students with a computer-based decision aid. J Cancer Educ 2011;26:82-91.

30. Meyer RM. Using adult learning concepts to assist patients in completing advance directives. J Contin Educ Nurs 2000;31:174-8. 